\title{
Determination of Heparin Using Norfloxacin-cerium Complex as a Fluorescence Probe by Spectrofluorimetry
}

\author{
Shailaja R. Patil, Umesh S. Mote, Shivajizao R. Patil, and Govind B. Kolekar \\ Fhorescence Spectroscopv Research Laboratorv, Department of Chemistry, Shivaj Lniversitv, \\ Kolhapur-11600+ (MS). India. ${ }^{*}$ E-mail: ghkolekar'a vahoo.co in \\ Received Mav 31, 2009, Accepted October 26, 2009
}

\begin{abstract}
A simple, rapid, practical and sensitive spectofluorimetric method was developed for the determination of trace amount of heparin (Hep). Under the Optimum conditions, we studied the interaction between NFLX-Ce ${ }^{3-}$-Hep complex by using absorption and fluorescence spectra. It was observed that Hep remarkably enhance the fluorescence intensity of the NFLX-Ce ${ }^{3-}$ conplex at $\lambda=356 \mathrm{~nm}$ in the buffer solution of $\mathrm{pH}=7.60$ and the enhancement effect is shown to relate with the concentration of $\mathrm{Hep}$. The linear range and detection limit for the detemination of Hep was obtained. By the Rosenthal graphic method, the association constant $(K)$ and binding numbers $(N)$ of Hep with probe were investigated. This method is relatively free of interference from coexisting substances and successfully applied for the determination of heparin in heparin sodium injection samples. A suitable mechanism of fluorescence enhancement between NFLX-Ce ${ }^{3+}$ and the NFLX-Ce ${ }^{3+}-\mathrm{Hep}$ systems were proposed and discussed.
\end{abstract}

Key Words: Heparin. Norfloxacin (NFLX), Cerium, Spectrofluorometric method

\section{Introduction}

Heparin (Hep) is a naturally-occurring anticoagulant produced by basophiles and mast cells. with a molecular weight ranging from $12000-15000 \mathrm{~g} / \mathrm{mol}$. It is a member of the glycosaminoglycan family of carbolydrates and consists of a variablysulfated repeating disaccharide unit. The most common disaccharide unit is composed of a 2-O-sulfated iduronic acid and 6-O-sulfated. N-sulfated. glucosamine. A highly-sulfated glycosaminoglycan. Hep is widely used as an injectable anticoagulant. The whole Hep molecule is negatively charged in aqueous solution and the average charge is -70 . It can also be used to form an inner anticoagulant surface on various experimental and medical devices such as test tubes and renal dialysis machines. Pharmaceutical grade Hep is derived from mucosal tissues of slaughtered meat of animals such as porcine (pig) intestine or bovine (cow) lung. It acts as an anticoagulant. preventing the formation of clots and extension of existing clots within the blood. It is one of the oldest dnigs in widespread clinical uses. Its discovery in 1916 predates the establishment of the United States Food and Drug Administration. although it did not enter clinical trials until 1935.

It was originally isolated from Canine liver cells hence its name (hepar is Greek word for "Liver") Heparin. Hep and its derivatives are effective for preventing thromboses and to cure urgent vein thrombus. ${ }^{2}$ It has variety of biological activities such as anticoagulant. antilipemic, antithrombotic. immunoregulatory, antipllogistic and antianaphylactic activities, etc. ${ }^{3}$ So Hep level in the patient's blood need to be carefully and accurately monitored during surgery and recovery. The reported methods of Hep determination focused on: Flowing injection analy sis. ${ }^{4}$ capillary chromatography ${ }^{5}$ surface plasmon resonance sensor analysis, ${ }^{6}$ membrane electrode via protamine titration and extracorporeal membrane oxygenation. ${ }^{8}$ The methods mentioned above have high fluorescence quantum y ield, large stokes shift. narrow emission bands and a large fluorescence lifetime. Hence. they avoid potential background fluorescent emission interference from the biological matrix. ${ }^{S}$ The some of researchers have been reported to detect the Hep by using

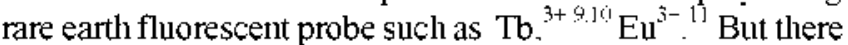
was no report on NFLX-Ce ${ }^{3-}$ complex as a fluorescent probe. Therefore a new method with high sensitivity and selectivity for the spectrofluorometric detennination of Hep is established.

In this paper. the interaction of NFLX-Ce ${ }^{3+}$-Hep fluorescence sy'stem was studied. Experimental results show that the characteristics peak of $\mathrm{Ce}^{3-}$ at $356 \mathrm{~nm}$ can be greatly enhanced and the enhancement effect is shown to relate with the concentration of Hep. This method is simple relatively free of interference from coexisting substances and can be successfully applied to determine the Hep in heparin sodium injection samples with satisfactory results. By using the Rosenthal grapluc method, the binding number and association constant of Hep with the probe has been estinated. The mechanism of fluorescence enhancement between NFLX-Ce ${ }^{3+}$ complex and NFLX-Ce ${ }^{3+}-\mathrm{Hep}$ were also studied.

\section{Experimental}

Reagents. All the reagents are of higher grade. The deionised. doubly distilled water was used through out the experiments. Hep was procured from s.d. fine-chem. Linuited Mumbai India. A stock solution of Hep ( $\left.1.0 \mathrm{mg} \cdot \mathrm{mL}^{-1}\right)$ was prepared directly' by dissolving appropriate amount of it in doubly distilled water. NFLX was obtained as a gift sample from planmaceutical companies and standard solution $2.20 \times 10^{-5} \mathrm{~mol} \cdot \mathrm{L}^{-1}$ was prepared by dissolving in a small amount of $\mathrm{HCl}$ and then diluted with distilled water. The stock solutions were stored at $0-4^{\circ} \mathrm{C}$

Aqueous stock solution of $\mathrm{Ce}^{3+}$ ion $1.0 \times 10^{-4} \mathrm{~mol} \cdot \mathrm{L}^{-1}$ was prepared by dissolving the cerium chloride with doubly distilled water. The Tris-HCl buffer solution $\left(0.1 \mathrm{~mol} \cdot \mathrm{L}^{-1}\right)$ was prepared 
by dissolving $2.424 \mathrm{~g}$ of tris $\mathrm{min} 100 \mathrm{~mL}$ volumetric flask with water and adjusted the $\mathrm{pH}$ with $\mathrm{HCl} / \mathrm{NaOH}$.

Apparatus. All fluorescence spectra were recorded on PC based spectrofluorometer (JASCO Japan FP-750) and absorption spectra were recorded with UV-Visible-NIR spectrophotometer (Shimadzu. Model UV-3600). The pH measurements were carried out on $\mathrm{pH}$ meter (model LI-10T Elico Pvt. Ltd. India).

General Procedure. An aliquot of standard $\mathrm{Ce}^{3+}$ solution $\left(1.0 \times 10^{-1} \mathrm{~mol} \cdot \mathrm{L}^{-1}\right)$ was taken into $10 \mathrm{~mL}$ calibrated tubes. followed by addition of $0.5 \mathrm{~mL} 2.20 \times 10^{-5} \mathrm{~mol} \cdot \mathrm{L}^{-1} \mathrm{NFLX}$ solutions. $1 \mathrm{~mL}$ of $10.0 \mu \mathrm{g} \cdot \mathrm{mL}^{-1}$ Hep solution and $0.5 \mathrm{~mL}$ buffer solution. The misture was diluted to $10 \mathrm{~mL}$ with doubly distilled water and allowed to stand for 10 minutes at room temperature. The fluorescence intensity was measured in a $1 \mathrm{~cm}$ quartz cell at $\mathrm{rex} / \mathrm{rem}=259 / 356 \mathrm{~mm}$. The excitation and emission slit width were kept constant at $10 \mathrm{~nm}$ for the measurement. The enlanced fluorescence intensity of NFLX $-\mathrm{Ce}^{3-}$ by Hep was represented as.

$$
\Delta \mathrm{F}=\mathrm{F}-\mathrm{F}_{\mathrm{o}}
$$

Here $\mathrm{F}$ and $\mathrm{F}_{\mathrm{o}}$ are the fluorescence intensities of the sy stems with and without Hep, respectively.

\section{Results and Discussion}

Fluorescence Spectra. Fluorescence excitation spectra and Fluorescence emission spectra of 1 . NFLX, 2. $\mathrm{Ce}^{3+}, 3 . \mathrm{Ce}^{3+}-\mathrm{Hep}$, 4. NFLX-Hep. 5. Ce ${ }^{3+}$-NFLX 6. Hep and 7. NFLX-Hep-Ce ${ }^{\text {?- }}$ are shown in Figure 1(a) and l(b) respectively. From the figure. it is observed that pure $\mathrm{Ce}^{3+}$ ion solution has a nearly no peak. In Fig. 1 comparing curve 1 with curve 5 , after the addition of NFLX into the $\mathrm{Ce}^{3-}$ ion solution. NFLX can form a binary complex with $\mathrm{Ce}^{3+}$ ion and observed the characteristic spectrum of $\mathrm{Ce}^{3-}$ ion appears at hex $=259 \mathrm{~nm}$ and $\lambda \mathrm{em}=356 \mathrm{~nm}$. The fluorescence intensities of $\mathrm{Ce}^{3+}$ ion at $356 \mathrm{~nm}$ can be enlhanced remarkably after the addition of Hep into the NFLX-Ce ${ }^{3+}$ system. which indicates that Hep can form a very stable ternary complex with the NFLX-Ce ${ }^{3+}$ binary complex.

Absontion Spectra. The absorption spectra of 1. NFLX, 2. $\mathrm{Ce}^{3+}$. 3. $\mathrm{Ce}^{3+}-\mathrm{Hep}$ 4. NFLX-Hep 5. NFLX-Ce ${ }^{3-}$. 6. Hep and 7 . NFLX-Ce ${ }^{3+}$-Hep are shown in Fig. 2. From Fig. it can be seen that curve 2, 3. and 6 all have nearly no peaks. The addition of $\mathrm{Ce}^{3-}$ increases the absorption but does not introduce any spectral changes in the absorption spectrum of NFLX. Similarly addition of Hep also enhance the absorption of NFX with slight blue spectral shift. These observations rules out the possibility of formation of NFLX-Ce ${ }^{3+}$ and NFLX-Ce ${ }^{3-}$-Hep complexes in the ground state. The excitation spectra of NFX without $\mathrm{Ce}^{3-}$ is identical spectrally with its absorption spectra. and exhibited pronounced blue shift after addition of $\mathrm{Ce}^{3-}$ and further addition of Hep the intensity seen to enhanced. These observation led us to consider the formation of NFLX-C $\mathrm{e}^{3-}$-Hep ternary complex.

Optimum Conditions. Effect of pH: The effects of various kinds of buffers on the fluorescence intensity of the system were tested and it was found that the Tris- $\mathrm{HCl}$ is the best for pro-
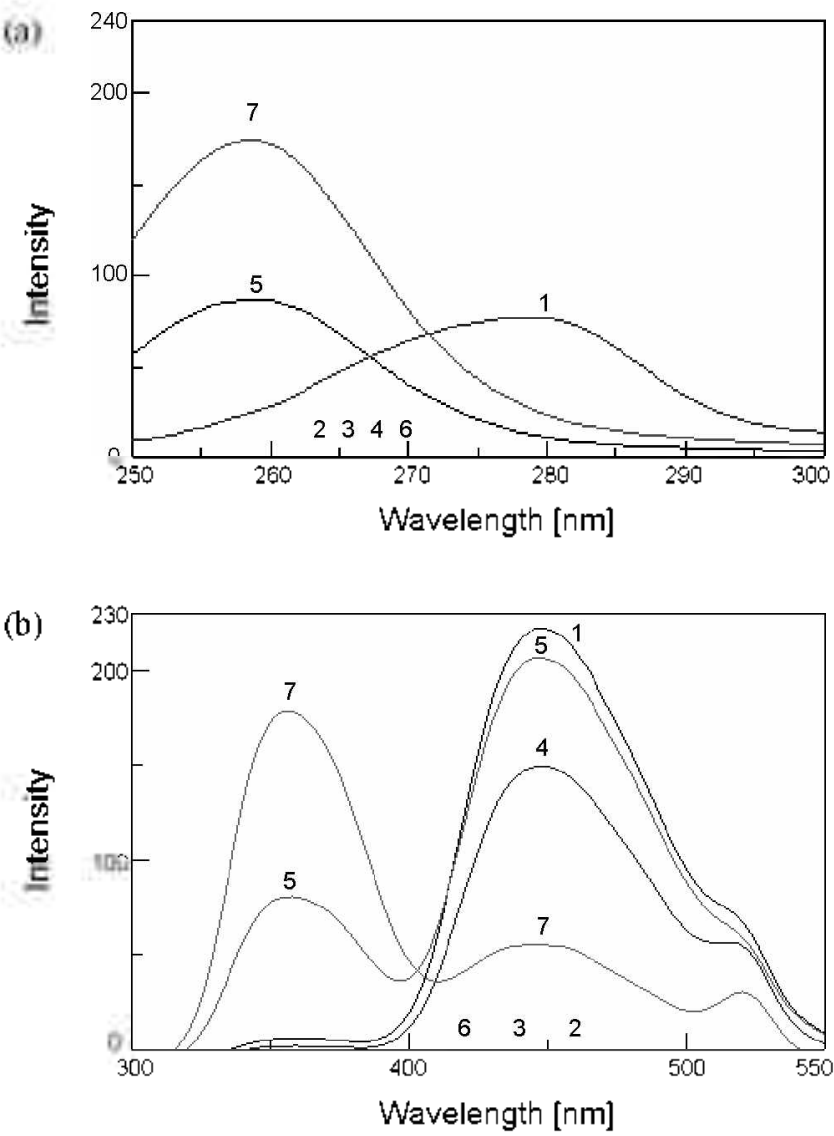

Figure 1. (a) Fluorescence Excitation spectra. 1: NFLX, 2: $\mathrm{Ce}^{3+}, 3$ $\mathrm{Ce}^{3-}$-Hep, 4: NFLX-Hep, 5: Ce $\mathrm{e}^{3-}$-NFLX, 6: Hep, 7: NFLX-Hep-Ce ${ }^{3-}$. Experimental condition: NFLX: $2.20 \times 10^{-9} \mathrm{~mol} \cdot \mathrm{L}^{-1}, \mathrm{Ce} \mathrm{e}^{3+}: 1.0 \times 10^{-1}$ $\mathrm{mol} \cdot \mathrm{L}^{-1}$, Hep: $10.0 \mu \mathrm{g} \cdot \mathrm{mL}^{-1}$, Bufter $\mathrm{pH}=7.60, \lambda \mathrm{eN} / \mathrm{hem}=259 \mathrm{~nm} /$ $356 \mathrm{~nm}$. (b) Fluorescence Envission spectra (7ev/em $=259 \mathrm{~nm} / 356 \mathrm{~nm}$ ). l: NFLX, 2:Ce $\mathrm{Ce}^{3+}$, 3: $\mathrm{Ce}^{3-}-\mathrm{Hep}, 4$ : NFLX-Hep, 5: Ce $\mathrm{e}^{3+}-\mathrm{NFLX}, 6$ : Hep, 7: NFLX-Hep-Ce $e^{3+}$.

posed system. The effect of $\mathrm{pH}$ on the fluorescence intensity is shown in Fig. 3. From the figure it is observed that the flourescence intensity was enhanced naximum in the range of $\mathrm{pH}$ 6.8 to 8.2 . Therefore the $\mathrm{pH} 7.6$ was fixed for further study.

Effect of NFLX Concentration: The effect of NFLX concentration on the fluorescence intensity of the system was studied when concentration of NFLX solution added in the range of $2.20 \times 10^{\circ} \mathrm{mol} \cdot \mathrm{L}^{-1}$ to $2.20 \times 10^{-6} \mathrm{~mol} \cdot \mathrm{L}^{-1}$ to the NFLX-Ce $e^{3-}$-Hep system, the fluorescence intensity reached maximum and remained constant. Thus $1.1 \times 10^{-6} \mathrm{~mol} \cdot \mathrm{L}^{-1} \mathrm{NFLX}$ was used for further study.

Effect of $\mathrm{Ce}^{3+}$ Ion Concentration: In order to study the effect of $\mathrm{Ce}^{3-}$ ion concentration. the fluorescence intensity measurement of the system was carried out by varying the concentration of $\mathrm{Ce}^{3+}$ ion from $1 \times 10^{-5} \mathrm{~mol} \cdot \mathrm{L}^{-1}$ to $2 \times 10^{-5} \mathrm{nol} \cdot \mathrm{L}^{-1}$ (Fig. 4). The result indicates that the maximum fluorescence intensity was observed in the studied concentration range. Hence all measurements were carried out at $1.5 \times 10^{-5} \mathrm{~mol} \cdot \mathrm{L}^{-1}$ for further study.

Effect of Equilibration Time: Equilibration time for completing the chelation reaction was varied between 5 to $30 \mathrm{mi}$ mutes at room temperature. The fluorescence intensity reached its maximum value and remained stable at least 2 hours then 


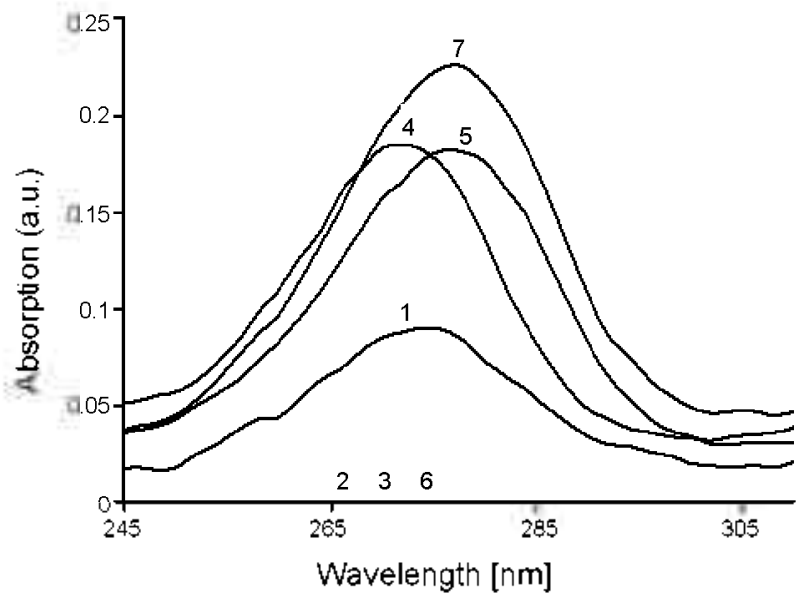

Figure 2. Absolption Spectra of (1) NFLX, (2) Ce $\mathrm{s}^{3-},(3) \mathrm{Ce}^{3-}-\mathrm{Hep},(4)$ NFLX-Hep, (5) NFLX-Ce ${ }^{3-}$, (6) Hep, (7) NFLX-Ce ${ }^{3+}$-Hep. Experimental condition: NFLX: $2.20 \times 10^{-5} \mathrm{~mol} \cdot \mathrm{L}^{-1}, \mathrm{Ce}^{3+}: 1.0 \times 10^{-7} \mathrm{~mol} \cdot \mathrm{L}^{-1}$, Hep: $10.0 \mu g \cdot m L^{-1}$, Buffer $p H=7.60$.

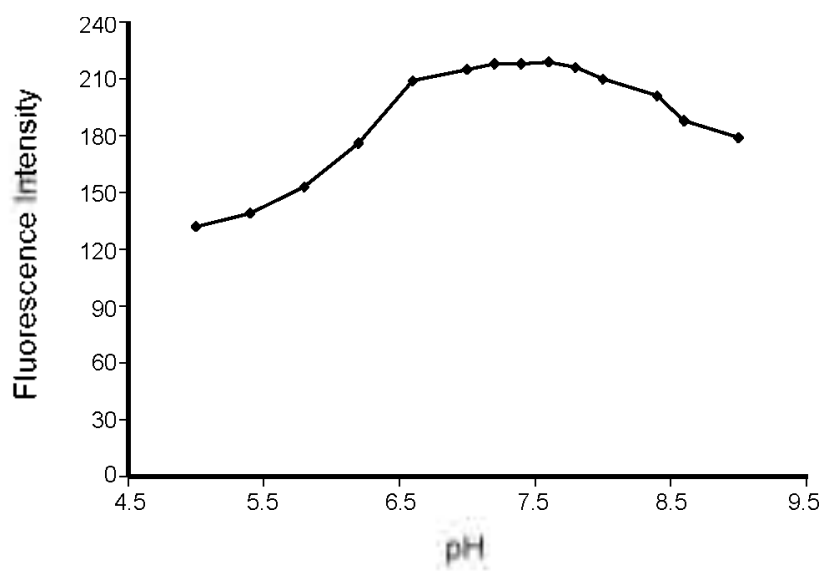

Figure 3. Eftect of $\mathrm{pH}$ on the enhanced fluorescence intensity; The Tr1s$\mathrm{HCl}$ buffer is used for $\mathrm{pH} 7.0-8.0$.

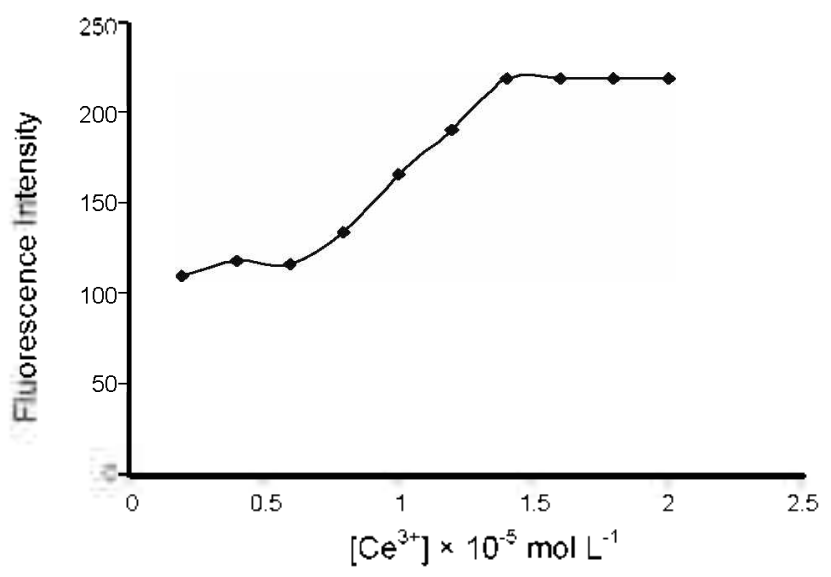

Figure 4. Effect of the concentration of $\mathrm{Ce}^{3+}$ on the enlanced fluorescence intensity. A $10 \mathrm{~mL}$ solution contains NFLX $\left(1.1 \times 10^{-5} \mathrm{~mol}\right.$. $\left.\mathrm{L}^{-1}\right), \mathrm{HEP}\left(1.0 \mu \mathrm{g} \cdot \mathrm{mL}^{-1}\right)$, buffer solution $(\mathrm{pH} 7.60)$ and $\mathrm{Ce}^{3-}\left(1.0 \times 10^{-6}\right.$ $\left.\mathrm{mol} \cdot \mathrm{L}^{-1}, 2.0 \times 10^{-5} \mathrm{~mol} \cdot \mathrm{L}^{-1}\right)$
Table 1. Effect of coexisting substances

\begin{tabular}{|c|c|c|c|}
\hline Sr. No. & $\begin{array}{l}\text { Coexisting } \\
\text { substance }\end{array}$ & $\begin{array}{l}\text { Concentration } \\
\left(m o l ~ L^{-1}\right)\end{array}$ & $\begin{array}{l}\text { Average Fluorescence } \\
\text { Intensity }(\Delta F \%)\end{array}$ \\
\hline 1 & $\mathrm{CO}^{2+}\left(\mathrm{Cl}^{-}\right)$ & $5.0 \times 10^{-5}$ & 2.5 \\
\hline 2 & $\mathrm{Cr}^{3-}\left(\mathrm{SO}_{4}{ }^{2 \cdot}\right)$ & $1.5 \times 10^{.5}$ & 20 \\
\hline 3 & $\mathrm{Mn}^{1+}$ & $5 \times 10-5$ & 6.55 \\
\hline 4 & $\mathrm{Fe}^{3-}\left(\mathrm{SO}_{4}^{2-}\right)$ & $9.0 \times 10^{-5}$ & -6.1 \\
\hline 5 & $\mathrm{Ni}^{2^{-}}$ & $6.8 \times 10^{-6}$ & -3.2 \\
\hline 6 & $\mathrm{Sn}^{4+}$ & $8.4 \times 10^{7}$ & 5.7 \\
\hline 7 & $\mathrm{Cu}^{2+}\left(\mathrm{SO}_{4}{ }^{2-}\right)$ & $1.6 \times 10^{-5}$ & 4.6 \\
\hline 8 & $\mathrm{Zn}^{-1+}\left(\mathrm{Cl}^{\circ}\right)$ & $1.1 \times 10^{.5}$ & 2.5 \\
\hline 9 & Tryptophan & $1.5 \times 10^{.5}$ & 3.88 \\
\hline 10 & $\mathrm{Al}^{3-}$ & $3.77 \times 10^{-5}$ & -0.25 \\
\hline 11 & $\mathrm{Ca}^{1+}\left(\mathrm{Cl}^{-}\right)$ & $5.00 \times 10^{-5}$ & -2.40 \\
\hline 12 & $\mathrm{Mg}^{2+}\left(\mathrm{SO}_{4}{ }^{1 \cdot+}\right)$ & $5.00 \times 10^{.5}$ & 5.10 \\
\hline 13 & HSA & $2.00 \times 10^{-7}$ & 4.50 \\
\hline 14 & Adenine & $1.04 \times 10^{8}$ & 5.20 \\
\hline 15 & Glucose & $1.00 \times 10^{.3}$ & -2.40 \\
\hline 16 & $\mathrm{Mo}^{6+}$ & $1.00 \times 10^{-5}$ & 3.69 \\
\hline
\end{tabular}

Table 2. Comparison of spectrofluorimetric methods for the determunation of Hep

\begin{tabular}{|c|c|c|c|}
\hline $\begin{array}{l}\text { Sr. } \\
\text { No. }\end{array}$ & Method & Linear range & $\begin{array}{l}\text { Detection } \\
\text { limit }\end{array}$ \\
\hline 1 & Flowing injection analysis & $0.12 \mathrm{mg} / \mathrm{mL}$ & $300 \mathrm{ng} / \mathrm{mL}$ \\
\hline 2 & Capillary chromatography & $0.50-44.1 \mathrm{mg} / \mathrm{mL}$ & $157.5 \mathrm{ng} / \mathrm{mL}$ \\
\hline 3 & $\begin{array}{l}\text { Surface plasmon resonance } \\
\text { sensor analysis }\end{array}$ & $1.26-12.6 \mathrm{mg} / \mathrm{mL}$ & $1260 \mathrm{ng} / \mathrm{mL}$ \\
\hline 4 & Curment method & $0.06-1.5 \mathrm{mg} / \mathrm{mL}$ & $60 \mathrm{ng} / \mathrm{mL}$ \\
\hline
\end{tabular}

decreases slowly. Hence all measurements were made at room tenperature within 2 hours.

Effect of Addition Order: The addition of various reagents in different orders has a great influence on the florescence intensity. Therefore considering the enhancement of fluorescence intensities of these systems the order of addition were maintained as: NFLX, Ce $\mathrm{e}^{3-}$, Hep and buffer.

Effect of Coexisting Sulstances: The effect of various cations and anions (coexist substances) commonly associated with the fluorescence of NFLX-Ce ${ }^{3-}$-Hep system was studied under optinum conditions. The criterion for interference was fixed at a $\pm 10 \%$ variation of average fluorescence intensity calculated for the established level of Hep. The tolerance limits for the tested ions are given in Table 1 and it can be seen that the most coexisting substances have no influence. ${ }^{11}$

\section{Analytical Application}

Linear Range and Limit of Detection. Limit of detection is the lowest quantity of substance that can distinguish from the absence of that substance within a stated confidence limit. Under the experimental conditions there was a linear relationship between fluorescence intensity and Hep concentration in the mange of 0.1 to $1.5 \mu \mathrm{g} / \mathrm{mL}$ with a correlation coefficient 0.9893 . 
(a)<smiles>Cn1cc(C(=O)O)c(=O)c2cc(F)c(N3CCNCC3)cc21</smiles>

(b)

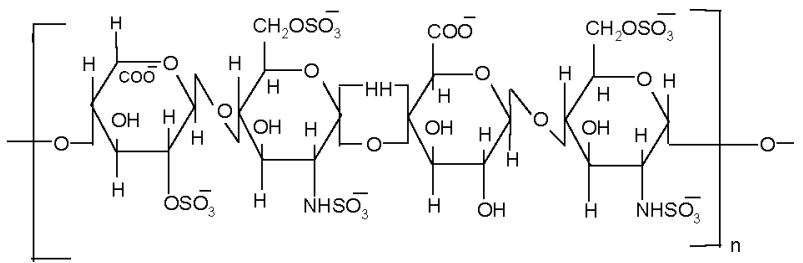

Figure 5. (a) Structure of Nortloxacin, (b) Structure of Heparin.

The limit of detection and standard deviation are $60 \mathrm{ng} / \mathrm{mL}$ and 0.287 respectively from a series of 10 reagents blanks. Experimental results are shown in Table 2 By comparison with other existing methods. it is observed that the proposed method has advantages over others considering following factors: good stability, high sensitivity and wide linear range.

Detemination of Heparin in Heparin Sodium Injection Sample. The developed method was applied for the determination of Hep in Hep sodium injection sample. For the assay of Hep. the sample must be diluted appropriately within the linear range of the determination of Hep and the sample solution was analyzed by the method developed above. using the standard calibration method. The average recovery and relative standard deviation for the determination of Hep from injection sample are $104.8(\%)$ and 0.3 respectively: This indicates the superiority of the proposed method over the other methods.

The Interaction Mechanism of the Complex NFLX-Ce ${ }^{3+}$ with Heparin The Formation of NFLX-Ce ${ }^{3+}$ Binary Complex: Norfloxacin [1-ethy 1-6-flouro-1-4-dilydro-4-oxo-7-(1-piperazinyl)-3-quinoline carboxylic acid] is broad spectrum antimicrobial fluoroquinolone. The antimicrobial spectrum of NFLX makes this drug attractive in veterinary therapy. NFLX reaches high levels in the urine and it is used in the treatment of urinary tract infections. The structure of NFLX is shown in Fig.5(a).

Norfloxacin is one kind of bacteriophage containing an $\alpha$ carbonyl carboxylic acid configuration. It is suitable for efficient energy transfer from ligand to $\mathrm{Ce}^{3+}$ ion. The high fluorescence quantum yield is observed due to large stokes shift, narrow emission bands and a large fluorescence life time and so avoid potential background fluorescent emission interferences from biological matrix. Therefore NFLX is an ideal ligand for $\mathrm{Ce}^{3+}$ ion and it can possibly sensitize the fluorescence intensity of $\mathrm{Ce}^{3-}$ ion via intra molecular energy transfer ${ }^{12}$.

The Fomation of NFLX-Ce ${ }^{3+}$-Hep Temary Complex: Hep is a naturally occurring biomacromolecule with an average molecular weight $15000 \mathrm{~g} / \mathrm{mol}$ and an average charge -70 . Hep is member of the glycosaminoglycan family of carbolydrates. It consists of repeating disaccharide units of glucuronic acid and glucosamine residues shown in Fig. 5(b).

Whole Hep molecule exists as a big polyvalent anionic state in water solution. Because Hep has 7 binding sites (five sulfate groups and two carbosyl groups) per tetrasaccharide unit. and the used Hep contains 42 monosaccharide units. the total binding number is $73.5(42 \times 7 / 4)$ per Hep molecule. ${ }^{3}$ Therefore a stable temary complex in close proximity to a large degree of molecular conjugation and rigid structure can be formed by the electrostatic interaction and coordination between Hep and NFLX$\mathrm{Ce}^{3+}$ binary complex.

Measurement of Association Constant and Binding Numbers: The Rosenthal graphic method ${ }^{13}$ was regarded as a modification of the Scatchard method. The equation for a Scatchard plot is slightly different from the equation for the Rosenthal plot. The Rosenthal graphic method was used to estimate the association constant $(\mathrm{K})$ and binding number $(\mathrm{N})$ of the biomacromolecule to the NFLX-Ce $e^{3-}$ probe. Briefly, when $C$, $C_{k}, C_{f}$ and $C_{C_{e}{ }^{3+}-\lambda F L Y}$ are constant biomacromolecule concentration in the system. the Hep bound, free and total concentration of the complex respectively. Then the Rosenthal plot shows equation (2)

$$
\frac{C_{b}}{C_{f}}=-\left(C_{C^{3+}-i T L Y}-C_{f}\right) K+N C K
$$

Because $C_{C^{3-}-N F L Y}=C_{3}+C_{f}$

then

$$
\frac{C}{C_{f}}=-\left(C_{C_{e}^{3+}-N F L Y}-C_{y}\right) K+N C K+1
$$

In the system. if $C_{C_{s^{3+}}{ }^{3+}+F_{L Y}}$ and $C_{f}$ are within the dynamic range of the calibration graph for NFLX-Ce ${ }^{3-}$-Hep complex, equation $(4)$ can be obtained

$$
\frac{F_{0}}{F}=-\left(1-\frac{F}{F_{0}}\right) C_{C e^{3-}-\mathrm{N} F L I} K+N C K+1
$$

$F, F_{o}$ are the intensities of the sy'stem with and without Hep. The plot of $\frac{F_{0}}{F}$ vs $\left(1-\left(\frac{F}{F_{0}}\right) C_{e^{3+}-s x y s}\right)$ can be obtained. The value of $\mathrm{K}$ and $\mathrm{N}$ are $2.80 \times 10^{4} \mathrm{~L} \cdot \mathrm{mol}^{-1}$ and 17.2 .

\section{Conclusions}

The experiment indicates that Hep can enhance the fluorescence intensity of NFLX- $\mathrm{Ce}^{3+}$ complex. Under the optimum condition the enhanced fluorescence intensity is in proportion to the concentration of Hep in the range 0.1 to $1.5 \mu \mathrm{g} / \mathrm{mL}$. In comparison with most of the reported fluorescence probe." $\mathrm{NFLX}-\mathrm{Ce}^{3-}$ has higher sensitivity and wide range. The proposed method has been successfully applied for the determination of Hep from pharnaceutical sanples directly. The interaction mechanism is also studied.

Aclnow ledgments. This work is supported by Department of Science \& Technology (DST) and University Grants Commi- 
ssion (UGC), New Delli under FIST and SAP respectively.

\section{References}

1. Mathison, S.: Bakker, E. Anal. Chem. 1999, 71, 4614.

2. Wang, R. Handbook of Chentical Prodicts; Medicament (part3): Peking China, 1999; p. 704.

3. Tiao, Q. C.: Liu, Q.: Sun, C.: He, H. Talamta 1999, 48, 1095

4. Nemcova, I: Rvchlovsky, P.; Havelcova, M.; Brabcova, M. Anal. Chint Acta 1999, t01, 223.

5. Zhou, X.: Liu, J.: Zhang, M.: Chen, S. Talanta 1998, 46, 757.
6. Gauls, K.: Hall, E. A. H. Biosen. Bioelect: 1998, 13, 1307.

7. Ramamurthy, N.; Baliga, N.; Wahr, T. A.; Schaller, U; Yang, V. C.; Meverhoft" M. E. Clin. Chem. 1998, it, 606.

8. Ambrose, T. M.; Parvin, C. A.: Mendeloff, E. L.: Luchtman-Jones, L. Chin. Chem. 2001, 47,858

9. Wei, W.: Wang. H., Jiang. C. Spctrochm Acta $42006,63,241$.

10. Wang, $H$; Wang, $Y$, Tiang, $C$. Anol. Letters 2005, 38, 167.

11. Zhu, X.; Wang X.; Jiang C. Anal. Biochent 2005, 341, 299

12. Richardson, F. S. Chem Rev $1982,82,541$.

13. Rosenthal. H. E. Anal. Biochem. 1967, 20.525.

14. Guo, Z. X.; Shen, H. X. Analust 1999, 124, 1093

15. Hao, Y. M: Shen, H. X. Spectrochint Acta part A 2000, $56,1013$. 